Document downloaded from:

http://hdl.handle.net/10251/65021

This paper must be cited as:

Tobon, JI.; Paya Bernabeu, JJ.; Restrepo, OJ. (2015). Study of durability of Portland cement mortars blended with silica nanoparticles. Construction and Building Materials. 80:92-97. doi:10.1016/j.conbuildmat.2014.12.074.

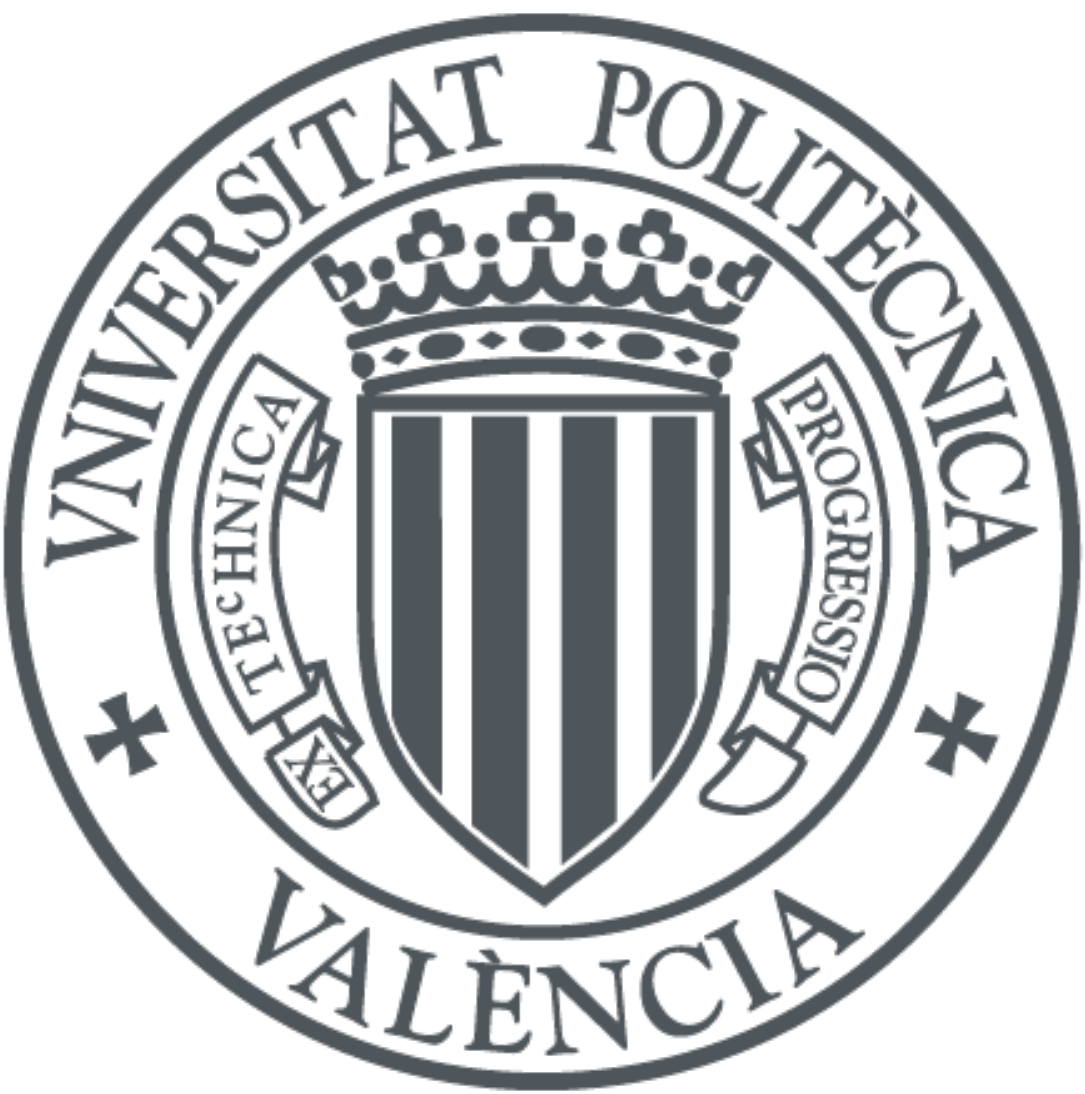

The final publication is available at

Copyright Elsevier

Additional Information 


\title{
STUDY OF DURABILITY OF PORTLAND CEMENT MORTARS BLENDED WITH SILICA NANOPARTICLES
}

\author{
Jorge I. Tobón ${ }^{1 *}$; Jordi Payá ${ }^{2} \&$ Oscar J. Restrepo ${ }^{1}$ \\ 1. Grupo del Cemento y Materiales de Construcción. Calle 75 \# 79ª-51, Bloque M17-101, Departamento de \\ Materiales y Minerales, Facultad de Minas, Universidad Nacional de Colombia, Medellín. \\ 2. Instituto de Ciencia y Tecnología del Hormigón, ICITECH. Camino de Vera s/n, Edificio 4N, Universitat \\ Politècnica de València, E-46022 Valencia, Spain.
}

\begin{abstract}
In this paper the effects of nanosilica (NS) on porosity, capillary suction (UNE 8398:2008), compressive strength (ASTM C 349), and sulfate resistance (ASTM C 1012) were evaluated for mortars made with Portland cement (control) and partially replaced with a commercial NS suspension, in percentages by weight of $0,1,3,5$, and $10 \%$. Mortars with a water/binder (w/b) ratio of 0.55 and addition of superplasticizer, for flow correction, were prepared. NS showed that, it has an important role in pore refining, decreasing the total volume of pores and their diameters. Samples containing NS showed an important positive effect on the capillary suction and sulfate resistance. In the case of expansion due to sulfate attack, mortars with 5 and $10 \%$ of NS decreased expansion by 90 and $95 \%$ respectively after two years of immersion.
\end{abstract}

KEYWORDS: Nanosilica, pozzolan, durability, sulfate resistance, blended cement, Portland cement

\footnotetext{
*Corresponding author: jitobon@unal.edu.co. Tel. \#(57-4) 425-5144, fax: (57-4) 425-5232
} 


\section{INTRODUCTION}

Nanosilica (NS) has been demonstrated to have a high pozzolanic reactivity, with important implications for the behavior of cement-based composites in fresh and hardened states. In the fresh state, it has been found that NS reduces setting times, increases the release of hydration heat, and modifies the rheological behavior of cement pastes and mortars [1-11]. In the hardened state, researchers have reported that NS increases the compressive strength $[1-4,6,12,13]$, decreases the porosity and improves some aspects of durability [4, 5, 8, 11, 14-18]. Some works have found that NS produces important mineralogical changes, mainly on C-S-H and portlandite (CH). For C-S-H, NS accelerates its formation, the samples blended with NS have a higher content of C-S-H, and it allows formation of longer C-S-H chains in comparison to the control samples [16-20].

In the evaluation of the incidence of NS on durability, most researchers have argued that, because this material has such good pozzolanic activity, it is possible to expect that NS will have a major impact on the durability of the mixtures made with. There are few studies published to date where researchers make a real assessment of the performance of cement blended with NS and that, the mortars are exposed to aggressive agents. Among the papers found those by Gaitero et al. [11] and Deyu Kong et al. [22] stand out, they evaluate the reduction of the calcium-leaching rate of cement paste by addition of silica nanoparticles. Other interesting investigations include those by MinHong et al. [1], Deyu Kong et al. [22], Said et al. [8], and Mostafa et al. [23], which analyze the resistance to chloride-ion penetration made on concrete of Portland cement blended with NS, and the work of Berra et al. [24], which studied the use of NS for preventing expansive alkali-silica reaction in concrete. Quercia et al [25], which found that some durability indicators like conductivity, chlorine migration and diffusion coefficients, and freeze-thaw resistance were significantly improved in self-compacting concrete (SCC) with addition of NS. Ibrahim Rahel et al. [26 have researched the effect of nanosilica on fire resistance of cement mortars. 
This work aims to discuss the results of the experimental evaluation of the effects of NS on porosity, water absorption, compressive strength, and sulfate resistance of Portland cement mortars. Regarding sulfate resistance, we show the evaluation of long term (more than two years) volumetric stability of mortars containing different percentages of NS immersed in a solution of magnesium sulfate (5 \% by weight). Magnesium sulfate $\left(\mathrm{MgSO}_{4}\right)$ is considered the most aggressive agent for the Portland cement [27]. The attack of the $\mathrm{MgSO}_{4}$ on C-S-H produces its decomposition to gypsum, brucite, and silica gel; this process is not directly related to ettringite formation [28]. There is a loss of strength and an adhesion into the cement paste, due to decalcification of C-S-H [28]. Hekal et al. [29] say that the decalcification of C-S-H, by the attack of magnesium sulfate, produces non-cohesive magnesium sulfate hydrate (M-S-H), as well as the expansion caused by the formation of expansive salts.

\section{MATERIALS AND METHODS}

In this work mortars of Colombian Ordinary Portland Cement (OPC), produced by Cementos Argos S. A., were prepared, with dry weight percentages of $0,1,3,5$, and $10 \%$ of commercial NS produced by BASF Chemicals Company. The nanosilica was presented as an aqueous suspension, with a suspended solids concentration of $40 \%$ on average and a $\mathrm{pH}$ of $10 \pm 1$ at $20^{\circ} \mathrm{C}$.

The durability (sulfate resistance and capillary suction) on mortars of cement with different percentages of substitutions of cement by NS was evaluated. Sulfate resistance was determined by measuring the longitudinal change in mortar bars with $0,1,3,5$, and $10 \%$ NS; mortar bars were immersed in a solution of $\mathrm{MgSO}_{4}$ with a concentration of $5 \%$, for 154 weeks, according to ASTM C1012 [30]. Capillary suction was evaluated on mortars, after 3 days of normal curing, with replacement of 0, 5, and $10 \%$ of cement by NS, according to UNE 8398:2008 [31]. Compressive 
strength was evaluated on mortars with 0,5 , and 10 wt. \% of substitution of cement by NS after 1 , 3, 7, and 28 normal curing days, according to ASTM C349-02 [32].

To evaluate durability and compressive strength mortars were prepared in accordance with the procedure in ASTM C305 [33]. Binder-to-Ottawa-sand (b/s) ratio used was 1/2.75, being binder (b) the sum of cement plus nanosilica. A constant water-to-binder (w/b) ratio of 0.55 was used. The w/b ratio was corrected for the amount of water incorporated by the suspension. To achieve a flow between 105 - $115 \%$ corresponding amount of superplasticizer (SP) required was incorporated (Table 1), according to ASTM C109 [34]. The superplasticizer (460 Pozzolith BASF Chemicals) was homogenized with the mixing water in order to achieve the optimum dispersion of the NSparticles in the mixes.

Table 1. Mixture proportions of mortars.

\begin{tabular}{|c|c|c|c|c|c|c|c|}
\hline \multirow[t]{2}{*}{ Sample } & \multirow{2}{*}{$\begin{array}{c}\text { Cement } \\
\text { (g) }\end{array}$} & \multirow{2}{*}{$\begin{array}{l}\text { NS } \\
\text { (g) }\end{array}$} & \multirow[t]{2}{*}{ b/s ratio } & \multirow[t]{2}{*}{$\mathrm{w} / \mathrm{b}$ ratio } & \multicolumn{2}{|c|}{ superplasticizer } & \multirow{2}{*}{$\begin{array}{l}\text { Flow } \\
(\%)\end{array}$} \\
\hline & & & & & (g) & $(\%)$ & \\
\hline Control & 500 & 0 & $1: 2.75$ & 0.55 & 1 & 0.2 & 114.8 \\
\hline $5 \% \mathrm{NS}$ & 475 & 25 & $1: 2.75$ & 0.55 & 3 & 0.6 & 106.0 \\
\hline $10 \% \mathrm{NS}$ & 450 & 50 & $1: 2.75$ & 0.55 & 13 & 2.6 & 110.4 \\
\hline
\end{tabular}

In order to evaluate the effect of NS on porosity, pastes with 0,5 , and $10 \mathrm{wt}$. \% of substitutions of cement by NS were prepared and evaluated by a Micromeritics Autopore IV Mercury Porosimeter. Samples were mixed manually with a w/b ratio of 0.4 and they were cured for 28 days at $20{ }^{\circ} \mathrm{C}$ and $98 \%$ relative humidity (RH). Seeking to improve the dispersion, the NS-particles suspension was pre-mixed with the mixing water. 


\subsection{CHARACTERIZATION OF MATERIALS}

The chemical composition of the materials used, cement and NS, are presented in Table 2. These analyses were carried out in an X-ray Fluorescence ARL 8680s Total Cement Analyzer using the wave dispersion method under standard ASTM C114-03 [35]. These results allowed conclude that, NS is high purity silica (Table 2).

Table 2. Chemical composition of materials

\begin{tabular}{|l|c|c|}
\hline Parameters (\%) & Cement & $\begin{array}{c}\text { Nanosilica } \\
\text { (NS) }\end{array}$ \\
\hline $\mathrm{SiO}_{2}$ & 20.13 & 93.56 \\
\hline $\mathrm{Al}_{2} \mathrm{O}_{3}$ & 4.37 & 0.00 \\
\hline $\mathrm{Fe}_{2} \mathrm{O}_{3}$ & 3.71 & 0.39 \\
\hline $\mathrm{CaO}$ & 64.30 & 0.22 \\
\hline $\mathrm{MgO}$ & 2,27 & 0.13 \\
\hline $\mathrm{Na}_{2} \mathrm{O}$ & 2.27 & 0.62 \\
\hline $\mathrm{K}_{2} \mathrm{O}$ & 0.31 & 0.02 \\
\hline $\mathrm{SO}_{3}$ & 1.99 & 0.30 \\
\hline Loss on ignition (LOI) & 2.44 & 4.46 \\
\hline Free lime (FL) & 0.33 & \\
\hline
\end{tabular}

The NS has mean particle size of $98.65 \mathrm{~nm}$, measurements were carried out in a Zetasizer of Malvern Instruments Ltd. The specific surface area (SSA) was determined in a Micromeritics Gemini 2380 by $\mathrm{N}_{2}$-physic-adsorption using BET method. Values of SSA found were $1.14 \mathrm{~m}^{2} / \mathrm{g}$ and $51.4 \mathrm{~m}^{2} / \mathrm{g}$ for the cement and the NS respectively.

The X-ray diffraction (XRD) of the mineral addition (Figure 1) was performed in a PANalytical $\mathrm{X}^{\prime}$ Pert PRO MPD, using a $2 \theta$ range of $2^{\circ}$ to $70^{\circ}$ with a step of $0.02^{\circ}$ and an accumulation time of 30 
s. It can be established that, NS has very low crystallinity and high purity. A broad peak was centered at $2 \theta=21.60^{\circ}$ and appeared as baseline deviation in the $2 \theta$ ranges $20.06^{\circ}$ and $26.50^{\circ}$.

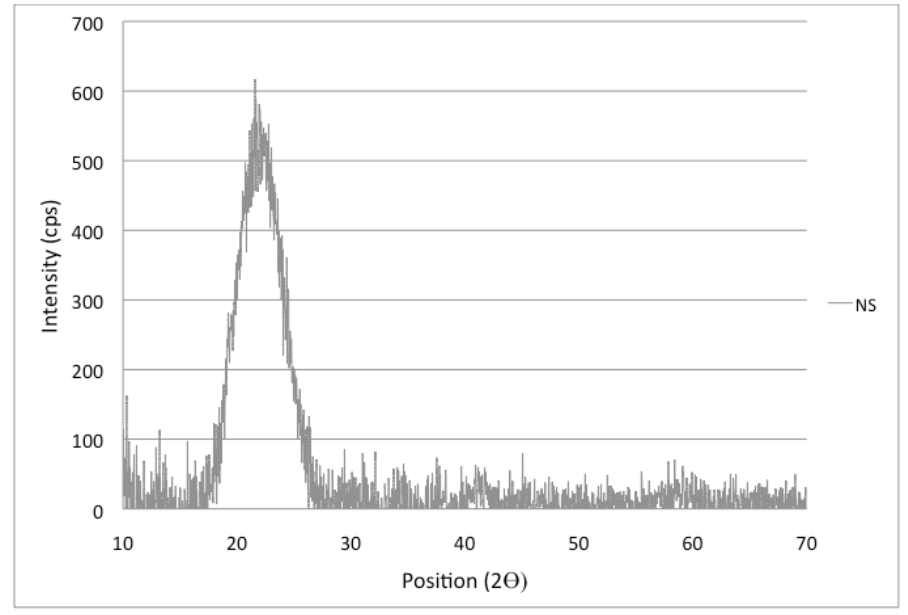

Figure 1. X-ray diffractogram of NS

Zeta potential was measured to different values of $\mathrm{pH}$ in order to evaluate the behavior of the NS dispersion when mixed with Portland cement (Figure 2); the suspension $\mathrm{pH}$ was modified using “ammonium hydroxide”. It can be seen that, NS suspension for $\mathrm{pH}$ between 7 and 14 is in the stable zone; potential values are lower than $-30 \mathrm{mV}$ [36-37], whereby, it is possible to conclude that, the NS will not agglomerate into the paste of Portland cement. 


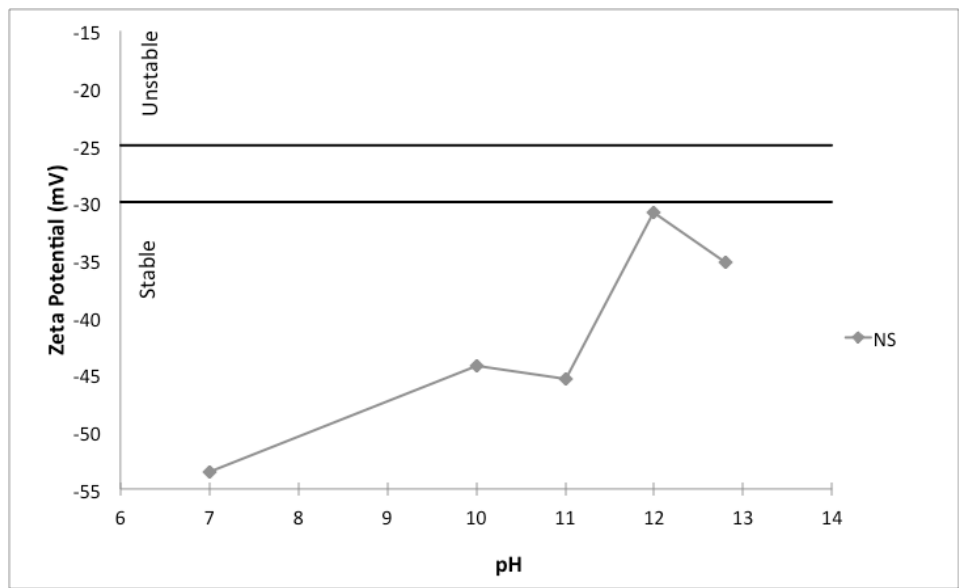

Figure 2. Zeta potential of the NS suspension for different values of $\mathrm{pH}$

\section{RESULTS AND DISCUSSION}

\subsection{CAPILLARY SUCTION}

This property controls the transport of fluid in the unsaturated concrete and depends on the concrete pore structure and type of fluid used [38]. Results of the tests of capillary suction (absorption of water with time) of the mortars prepared with cement (control) and blended cements (5 and 10 wt. $\%$ of NS), after three curing days are presented in Figure 3. 


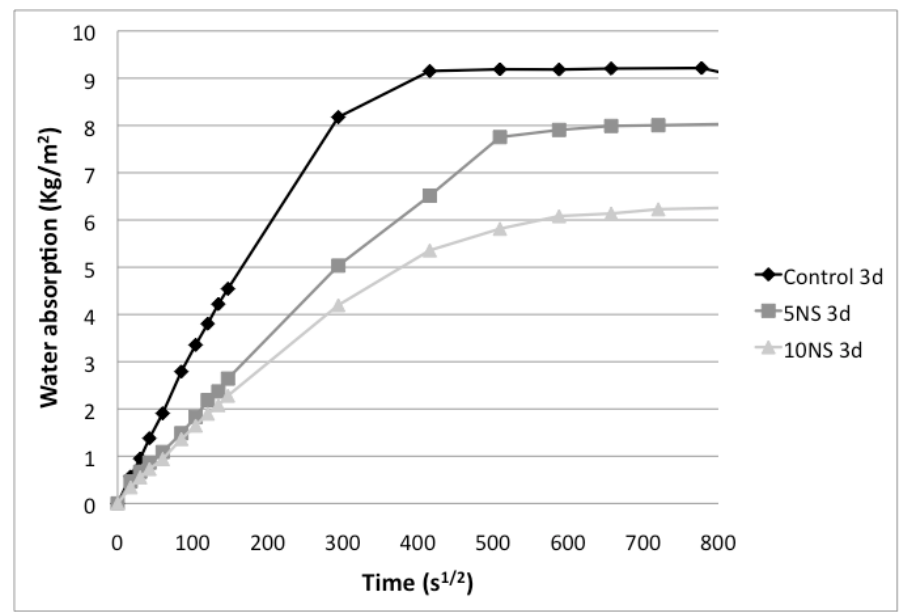

Figure 3. Capillary suction of different mortars after three curing days: control mortar (control 3d), 5 wt. \% of NS replaced (5NS 3d) and 10 wt. \% of NS replaced (10NS 3d)

There is a significant decrease in absorption rate and noteworthy differences in the quantity of absorbed water at the end of the test with the increase of substitution of the cement by NS (Figure 3). This fact is evidenced because the slope the first part of the curves of capillary suctions (between 0 and $300 \mathrm{~s}^{1 / 2}$ ), which is associated to the water absorption rate, decreases with the increase of NS percentage in mixes (control $=0.026 \mathrm{Kg} / \mathrm{m}^{2} \mathrm{~s}^{1 / 2}$, $5 \mathrm{NS}=0.018 \mathrm{Kg} / \mathrm{m}^{2} \mathrm{~s}^{1 / 2}$, and $10 \mathrm{NS}=0.012$ $\mathrm{Kg} / \mathrm{m}^{2} \mathrm{~s}^{1 / 2}$ ), showing that, the mortar with $10 \mathrm{wt}$. \% of NS has less than half the water absorption rate in comparison with the control sample. Additionally, total water absorption also decreases with the content of NS as shown by the values after $500 \mathrm{~s}^{1 / 2}$, 5NS shows a reduction of $11.1 \%$ and $10 \mathrm{NS}$ of $33.3 \%$ in comparison with the control sample.

This behavior of the NS shows as this mineral addition has a significant effect on refinement of pores, i.e., NS decreased mortars permeability, due to the rupture of the pore interconnections. Furthermore, NS seems to produce a decrease of total volume of pores. These effects of NS are due to its high specific surface area, their small particle size and good particle dispersion within cement 
pastes. Thus facilitating chemical reactions necessary to produce a high bulk density cementitious matrix with more C-S-H and less calcium hydroxide $(\mathrm{CH})$, as was suggested by Ozyildirim and Zegetosky [39]. This must be added to a physical effect of filler as was claimed by Gaitero et al. [21]. In order to assess the evolution of their porosity, the samples were assayed in a Mercury Intrusion Porosimeter (MIP).

\subsection{STUDY OF MERCURY INTRUSION POROSIMETRY (MIP)}

The mercury intrusion porosimetry technique (MIP) was carried out to evaluate the total volume of pores in percentage in cement pastes with and without NS (Table 3). In addition, from the MIP measurements the porosity, the pore-size distribution and the pore network can be analyzed. In the case of pastes, mortars or concretes the pore structure affects the mechanical behavior, permeability and durability of them [40].

Table 3. Total porosity of pastes (w/b=0.4, 28 days curing time)

\begin{tabular}{|c|c|}
\hline Samples & Total porosity (\%) \\
\hline Control & 19.18 \\
\hline $5 \mathrm{NS}$ & 19.74 \\
\hline $10 \mathrm{NS}$ & 16.84 \\
\hline
\end{tabular}

Values of total porosity for the control sample and sample with 5 wt. \% of NS are almost equal. The sample with 10 wt. \% of NS substitution achieves $12 \%$ reduction in the total porosity with respect to the control sample.

Gaitero et al. [41] proposed that, the porosity in pastes with NS decreases because the nanoparticles work as fillers in the space between the grains, and although they are very small to improve the efficiency of packing by themselves, NS-particles serve as nucleation sites for the growth of the 
hydration products and these products are responsible for reducing porosity. The fact is that, due to the pozzolanic activity of NS the amount of C-S-H gel increases because of the reaction of NS with portlandite, as was reported previously by Tobón et al. [19]. This fact helps one to understand that, the porosity decreases in pastes because portlandite with a laminar structure tends to pack more freely than the C-S-H gel. Besides, the quantity of water required for calcium ions in the C-S-H gel is greater than that in the portlandite, which reduces the free water, which is the main cause of the formation of pores [21].

MIP allows comparisons of the distribution of pore size. Figure 4 shows the differential volume of mercury intrusion versus pore diameters obtained for the different samples, which is a useful representation to determine pore size groupings and quantity of pores.

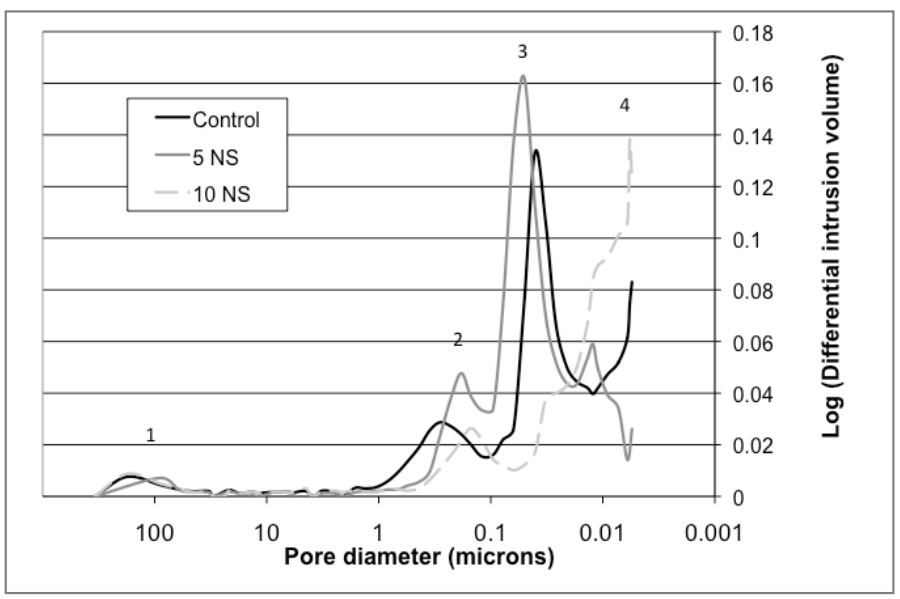

Figure 4. Pore-size distribution of the studied samples

In the samples, four families of pore size can be identified, represented in the graph peaks, where the differential intrusion volume is greater than zero: family 1 , around $150 \mu \mathrm{m}$ diameter; family 2 , 
about $0.2 \mu \mathrm{m}$ diameter; family 3, around $0.04 \mu \mathrm{m}$ diameter; and the family 4 , about $0.005 \mu \mathrm{m}$ diameter.

Some authors like Pedeferri and Bertolini [42], Mindess et al. [43], and Cabeza et al. [44] have proposed the following classification for pores according to their size: gel pores under $10 \mathrm{~nm}$ (family 4 in this case), capillary pores with diameters between $10 \mathrm{~nm}$ and $1.0 \mu \mathrm{m}$ (families 2 and 3) and pores greater than $1.0 \mu \mathrm{m}$ (family 1). They emphasized the importance of this classification from the viewpoint of the durability of concrete, since most of the mass transfer through the concrete take place through the capillary pores, whereas the gel pores practically do not contribute to transport. In this respect, other researchers as Hou et al. [18] have established a linear relationship between the volume of capillary pores and transport properties in cement pastes. Pores larger than $1.0 \mu \mathrm{m}$ are associated with air voids and consequently they are considered coarse pores.

Curves depicted in Figure 4 show that, for the sample with 10 wt. \% of NS, the mineral addition has produced an important pore refinement: decreases the maximum pore diameter of the family 2 (it goes from $0.28 \mu \mathrm{m}$ to $0.15 \mu \mathrm{m}$ for the control sample and the sample with $10 \mathrm{wt}$ \% of NS respectively), virtually disappear the pores of family 3 and favors the formation of much smaller pores (family 4 of $5 \mathrm{~nm}$ in diameter approximately) with respect to the control sample. This suggests the formation of new phases that fill the pores wholly or partially. From the viewpoint of durability this is very important because the capillary porosity virtually disappears in the sample and this kind of porosity moves toward gel pores. This reduction in the diameter of the pores means that, these pastes have a high capillary impermeability, hindering access of aggressive agents to its interior and increasing resistance to deterioration by chemical action. 
In the sample with $5 \mathrm{wt}$. \% of NS a pore refinement was also generated, but not so significantly as in the previous case: 5 wt. \% of NS decreased the average diameter of the family 1 (diameter changes from $170 \mu \mathrm{m}$ to $90 \mu \mathrm{m}$ in comparison to the control sample) and family 2 (goes from 0.28 $\mu \mathrm{m}$ to $0.18 \mu \mathrm{m}$ ). Moreover, $5 \mathrm{wt}$. \% of NS favors the formation of pores of $50 \mathrm{~nm}$ (family 3 ) and 12 $\mathrm{nm}$ (family 4).

This result on decreased volume of capillary pores agrees with the findings of authors like Ghafari et al. [45], which have obtained results in this direction for ultra-high performance concrete (UHPC) blended with NS.

Figure 5 shows the behavior of the pastes during the process of intrusion (continuous line) and extrusion (dashed line) of the mercury in the porosimetry test.

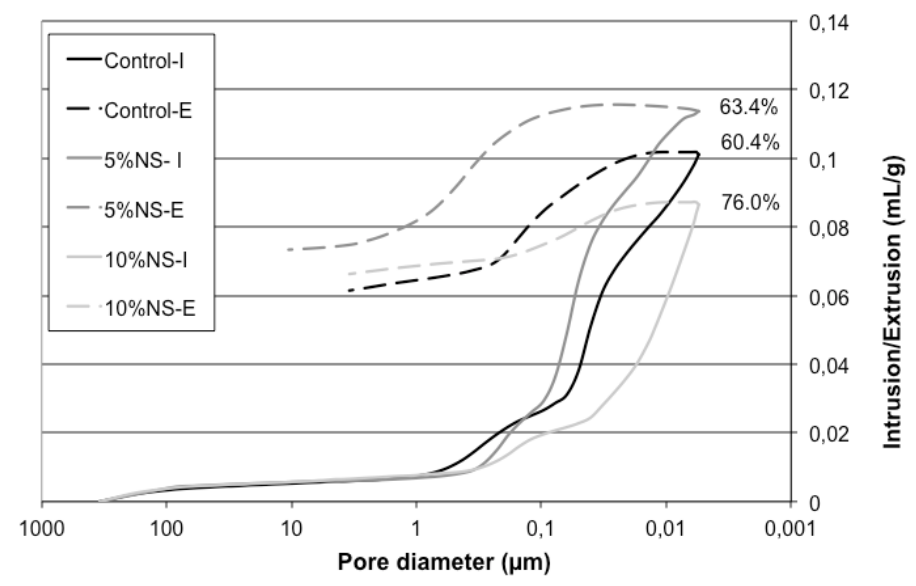

Figure 5. Intrusion (solid lines) and extrusion (dashed lines) curves in the MIP tests

In Figure 5 one can see that for pore diameters less than $0.3 \mu \mathrm{m}$, the intrusion curve for the sample with 5 wt. \% of NS (5\%NS-I), has a higher slope, showing that, in this range of diameters its pore 
volume is higher. These curves also confirm the decrease in the pore volume and their diameter in the sample with 10 wt. \% of NS (10\%NS-I), reflected in lower slopes and a rightward shift, i.e. towards smaller pore diameters.

When the combined effect of the mercury intrusion and extrusion in each sample is evaluated (Figure 5), it is seen that, much of the mercury remains into the sample when the pressure is decreased, in the case of this control sample the value was $60.4 \%$. The effect of this nanoparticle is primarily represented in the increase of the percentage of mercury retained in the extrusion process $63.4 \%$ for sample with 5 wt. \% of NS and $76.0 \%$ for the sample with 10 wt. \% of NS. The percentage of retained mercury increases with increasing percentage of cement replacement by NS. This behavior suggests a greater tortuosity as a result of the refined pore system. That is, the pores lost some of their connections and suffer a decrease in their diameter, due to the effect of the NS. This effect prevents the mercury, which came under pressure, to easily escape from the network of pores during the extrusion process.

\subsection{COMPRESSIVE STRENGTH DEVELOPMENT}

Control mortar achieved a compressive strength of 12.85, 24.16, 36.46, and 47.83 MPa at 1, 3, 7, and 28 days respectively. The compressive strength of the mortar containing NS (5 and 10 wt. \% replacements) was compared according to the calculation of the improvement in compressive strength as follows (1):

$$
I=\frac{S b s * 100}{S c s * C}-100
$$

Where:

I: improvement in compressive strength (\%) 
Sbs: compressive strength of blended sample (MPa)

Scs: compressive strength of control sample (MPa)

C: cement content in the blended sample

In Figure 6 the improvement of compressive strength of the blended samples with NS in comparison to the control sample is shown. For all curing times (1, 3, 7, and 28 days), the change was positive, i.e., NS produced a significant improvement of compressive strength for blended samples, at early and late ages. This behavior is a result of high pozzolanic activity of NS, which allows an increase the quantity of C-S-H. This increase of C-S-H plus the filler effect of NS, modifies the network of pores. The improvement of compressive strength is significantly higher in samples with 10 wt. \% of NS, they achieve an increase of almost $120 \%$ in comparison to the control sample after 1 curing day and at other curing ages the increment is close to $80 \%$. These results are consistent with those found in capillary suction and MIP, where 10 wt. \% of NS produced higher pore refinement.

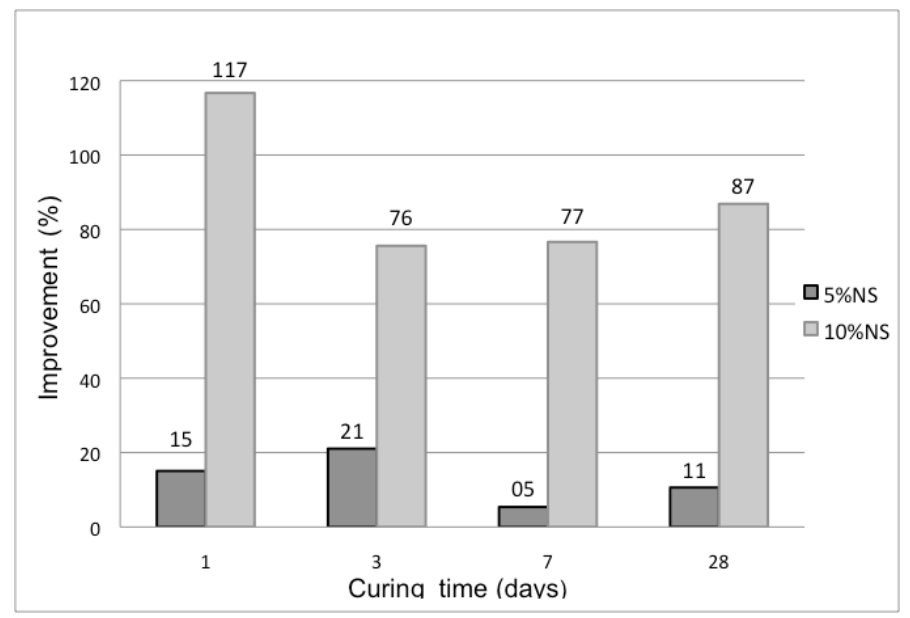

Figure 6. Improvement of the compressive strength for samples blended with NS 


\subsection{SULFATE RESISTANCE}

Control mortar and mortars with NS (1, 3, 5, and 10 wt. \% of replacements) were exposed to sulfate attack by immersion in $5 \% \mathrm{MgSO}_{4}$ solution for 154 weeks. The expansion was measured each one or two weeks. Expansion values in mortars produced by sulfate attack are graphically shown in Figure 7. As can be seen, the expansion decreased as the percentage of cement replacement by NS increased. In the last week (154) with the replacement of only 1 wt. \% of NS a $49 \%$ reduction in expansion was achieved, with 3 wt. \% of NS the expansion was $63 \%$ lower, and with 5 wt. \% of NS the expansion was $83 \%$ lower in comparison to the control sample. For the samples with 5 and 10 wt. \% of NS, the expansion after 100 weeks of immersion was not very important ( 0.29 and 0.15 \% respectively) compared to $2.82 \%$ that the control sample expanded, namely, mortars decreased expansion by 90 and $95 \%$, respectively. These expansion values for NS mortars were much lower than expected by the dilution effect. From this it can be stated that, with only 5 wt. \% of cement replacement by NS the expansion can be controlled in mortars subjected to $\mathrm{MgSO}_{4}$ attack.

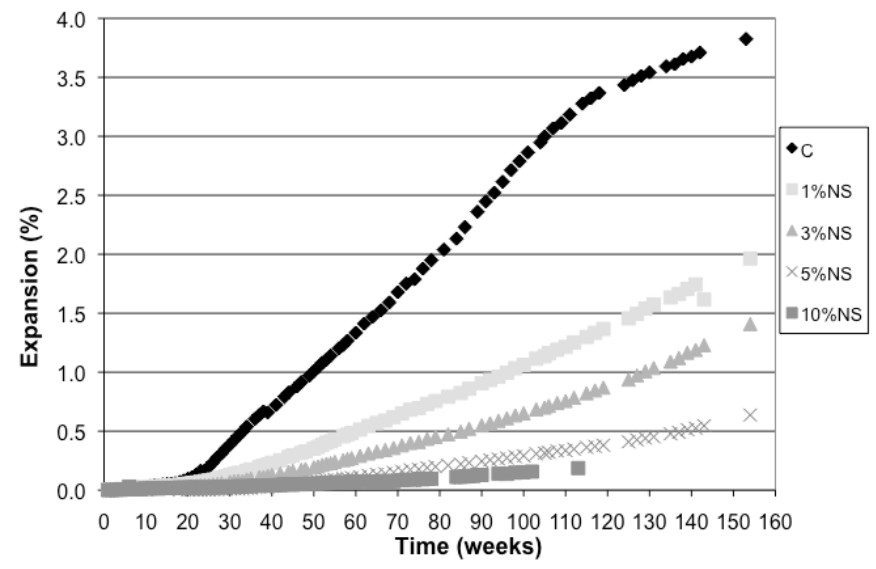

Figure 7. Expansion of mortars immersed in $5 \%$ magnesium sulfate solution

The behavior of mortars with and without cement replacement by NS was equal in terms of expansion up to approximately 20 weeks (Figure 7), thereafter the expansions increased at different 
rates in accordance with the mixture. Expansion value of $0.1 \%$ has been identified as important for possible initial degradation; this value is achieved for control sample at 20 weeks, for 5 wt. \% of NS sample at 57 weeks and for 10 wt. \% of NS sample at 77 weeks (Figure 7), this shows that, NS can make an Ordinary Portland Cement (OPC) resistant to sulfate attack (ACI C201-2R).

Percentages of expansion according to the NS replacement ratios in mortars for weeks $25,50,75$, and 100 of immersion in $5 \% \mathrm{MgSO}_{4}$ solution are shown in Figure 8.

Samples with NS exhibited a decreasing trend of expansion with increasing substitution percentage, which leads to a very low expansion, for the sample with 10 wt. \% of NS. Even after 100 weeks of immersion, NS produces an expansion decrease above $60 \%$ just with a 1 wt. \% substitution and an expansion decrease close to $95 \%$ with a 10 wt. \% substitution (Figure 8).

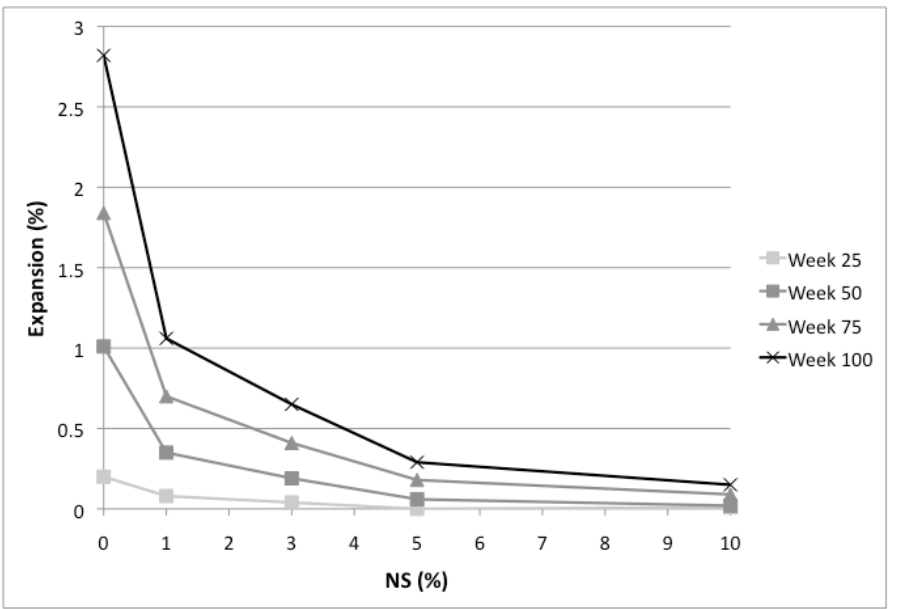

Figure 8. Correlation between the percentage of replacement and expansion after 25, 50, 75, and 100 weeks of immersion in $5 \% \mathrm{MgSO}_{4}$ solution

\section{FINAL DISCUSSION}


Results showed that, from 5 wt. \% substitution of cement by NS significantly reduced the total porosity in pastes and mortars of Portland cement, but more importantly the NS produced a pore refining of the cementitious matrices, mainly reducing the percentage of capillary pores and increasing gel pores.

This effect on the pore structure is very important for the performance of mortars, because the size of the pores that most affect the durability and the compressive strength of mortars are the capillary pores, and as it was demonstrated in this research the NS practically eliminated this kind of pores.

Regarding durability, the fact that the gel pore size was increased mean that most aggressive agents cannot penetrate the cementitious matrix, due to that the pores have very small diameter. This happens to $\mathrm{MgSO}_{4}$, which is unable to penetrate the cement matrix and cannot break the C-S-H to generate expansive salts, for this reason the mortars with NS have lower expansion after the aggressive attack of these sulfates in comparison with mortars of OPC without NS. Furthermore, thanks to pore refining, NS reduces the absorption rate, which means that, any damage that might occur in mortar will be slower over time.

\section{CONCLUSIONS}

Nanosilica particles produced a significant refinement of pores, defined as the breakdown of interconnections among them and decreased the total pore volume, which resulted in a lower absorption rate and a smaller total absorption of fluids by mortars.

It is noteworthy that the pore sizes that are most diminished due to the effect of NS are those known as capillary pores, NS helps the formation of pores with diameters below $10 \mathrm{~nm}$, called gel pores, 
which have a very positive effect on the compressive strength and durability (evaluated by sulfate resistance). With 10 wt. \% of NS the capillary porosity practically disappeared.

The improvement of compressive strength is significantly higher in samples with $10 \mathrm{wt}$ \% of NS, after 1 curing day they achieve an increase near to $120 \%$ in comparison to the control sample and at other curing ages the increment is close to $80 \%$.

In the assessment of sulfate resistance, it was found that, mortars with 5 and 10 wt. \% NS decreased expansion by 90 and 95 \% respectively after two years of immersion. For this reason, it is possible to say that, this replacement fraction, using this type of NS, is sufficient to control the expansion by $\mathrm{MgSO}_{4}$ attack and to make an ordinary Portland cement a sulfate resistant cement (ACI C201-2R).

\section{ACKNOWLEDGMENTS}

The authors express their sincere thanks to Cementos Argos S. A. of Colombia and COLCIENCIAS (Project 20201007768) for their logistical and financial support for this project. In addition, we want to thank the Engineer Carolina Giraldo and the Departamento de Ingeniería de la Construcción at Universidad de Alicante - Spain for their invaluable collaboration in laboratory tests.

\section{REFERENCES}

[1] Min-Hong Z., Jahidul I., and Sulapha P. "Use of nano-silica to increase early strength and reduce setting time of concretes with high volumes of slag", Cem Concr Compos 2012; 34 (5): 650-662.

[2] Berra M, Carassiti F, Mangialardi T, Paolini AE, and Sebastiani M, Effects of nanosilica addition on workability and compressive strength of Portland cement pastes, Constr Build Mater 2012; 35: 666-675. 
[3] Tobón J.I, Restrepo J, \& Payá J. Comparative analysis of performance of Portland cement blended with nanosilica and silica fume. DYNA 2010; 163: 37-46.

[4] Ali Nazari \& Shadi Riahi. The effects of $\mathrm{SiO}_{2}$ nanoparticles on physical and mechanical properties of high strength compacting concrete. Composites: Part B 2011; 42: 570-578.

[5] Mounir Ltifi, Achraf Guefrech, Pierre Mounanga, \& Abdelhafid Khelidj. Experimental study of the effect of addition of nano-silica on the behaviour of cement mortars. Procedia Engineering 2011; 10: 900-905.

[6] Naji Givi A, Abdul Rashid S, Nora A. Aziz F, Amran Mohd Salleh M. The effects of lime solution on the properties of $\mathrm{SiO}_{2}$ nanoparticles binary blended concrete. Composites: Part B 2011; 42: 562-569.

[7] Senff L, João A.L, Victor M.F, Dachamir H, and Wellington L.R. Effect of nano- silica on rheology and fresh properties of cement pastes and mortars, Constr Build Mater 2009; 23(7): 2487-2491.

[8] Said A.M, Zeidan M.S, Bassuoni M.T, Tian Y. Properties of concrete incorporating nano-silica. Constr Build Mater 2012; 36: 838-844.

[9] Peng-kun Hou, Shiho Kawashima, Ke-jin Wang, David J. Corr, Jue-shi Qian, Surendra P. Shah. Effects of colloidal nanosilica on rheological and mechanical properties of fly ash-cement mortar. Cem Concr Compos Cem Concr Compos 2013; 35: 12-22.

[10] Quercia G, Hüsken G, Brouwers H.J.H. Water demand of amorphous nano-silica and its impact on the workability of cement paste. Cem Concr Res 2012; 42(2): 344-357.

[11] Abd.El.Aleem S, Heikal M, Morsi W.M. Hydration characteristic, thermal expansion and microstructure of cement containing nano-silica. Construction and Building Materials 2014; 59: 151-160. 
[12] Byung-Wan J, Chang-Hyun K, Ghi-Ho T \& Jong-Bin P. Characteristics of cement mortar with nano$\mathrm{SiO}_{2}$ particles. Constr Build Mater 2007; 21: 1351-1355.

[13] Stefanidou M \& Papayianni I. Influence of nano- $\mathrm{SiO}_{2}$ on the Portland cement pastes. Composites: Part B 2012; 43: 2706-2710.

[14] Ji, Tao. Preliminary study on the water permeability and microstructure of concrete incorporating nano$\mathrm{SiO}_{2}$. Cem Concr Res 2005; 35: 1943-1947.

[15] Li, H.; Xiao, H.; Yuan, J \& Ou, J. Microestructure of cement mortar with nanoparticles. Composite Part B: engineering 2004; 35: 185-189.

[16] Qing Y, Zenan ZH, Deyu K. \& Rongshen CH. Influence of nano- $\mathrm{SiO}_{2}$ addition on properties of hardened cement paste as compared with silica fume. Constr Build Mat 2007; 21: 539-545.

[17] Mukharjee B.B, Barai S.V. Assessment of the influence of Nano-Silica on the behavior of mortar using factorial design of experiments. Construction and Building Materials 2014; 68: 416-425.

[18] Hou P, Cheng X, Qian J, Zhang R, Cao W, Shah S.P. Characteristics of surface-treatment of nano-SiO 2 on the transport properties of hardened cement pastes with different water-to-cement ratios. Cement \& Concrete Composites 2015; 55: 26-33.

[19] Tobón J.I, Payá J, Borrachero M.V and Restrepo O.J. Mineralogical evolution of Portland cement blended with silica nanoparticles and its effect on mechanical strength. Constr Build Mat 2012; 36: 736-742.

[20] Bjornstrom J, Martinelli A, Matic A, Borjesson L, and Panas I. Accelerating effects of colloidal nanosilica for beneficial calcium-silicate-hydrate formation in cement. Chem Phys Lett 2004; 392(1-3): 242248. 
[21] Gaitero JJ, Campillo I, Guerrero A. Reduction of the calcium leaching rate of cement paste by addition of silica nanoparticles. Cem Concr Res 2008; 38(8-9): 1112-1118.

[22] Deyu Kong, Xiangfei Du, Su Wei, Hua Zhang, Yang Yang, Surendra P. Shah. Influence of nano-silica agglomeration on microstructure and properties of the hardened cement-based materials. Constr Build Mat 2012; 37: 707-715.

[23] Mostafa Jalal, Esmaeel Mansouri, Mohammad Sharifipour, Ali Reza Pouladkhan. Mechanical, rheological, durability and microstructural properties of high performance self-compacting concrete containing $\mathrm{SiO}_{2}$ micro and nanoparticles. Materials and Design 2012; 34: 389-400.

[24] Berra M, Carassiti F, Mangialardi T, Paolini AE, Sebastiani M. Use of nano-silica for preventing expansive alkali-silica reaction in concrete. In: Maarten A.T.M. Broekmans, Børge J. Wigum, editors. Proceedings of $13^{\text {th }}$ International Conference on Alkali-aggregate Reaction in Concrete, Trondheim, Norway; 2008.

[25] Quercia G, Spiesz P, Hüsken G, Brouwers H.J.H. SCC modification by use of amorphous nano-silica, Cement \& Concrete Composites 2014; 45: 69-81.

[26] Ibrahim Rahel Kh, Hamid R, Taha MR. Fire resistance of high-volume fly ash mortars with nanosilica addition. Constr Build Mater 2012;36:779-86. 
[27] Ganjian, E. and Sadeghi, H. Effect of magnesium and sulfate ions on durability of silica fume blended mixes exposed to the seawater tidal zone. Cem Conc Res 2005; 35: 1332-1343.

[28] Collepardi M. A state-of-the-art review on delayed ettringite attack on concrete. Cem Concr Compos 2003; 25(4-5): 401-407.

[29] Hekal E.E, Kishar E., Mostafa H. Magnesium sulfate attack on hardened blended cement pastes under different circumstances. Cement and Concrete Research 2002; 32: 1421-1427.

[30] ASTM C 1012 - 02. Standard test method for length change of hydraulic-cement mortars exposed to a sulfate solution. 2002. 5P. ASTM International, United States of America.

[31] UNE 8398:2008. Durabilidad del hormigón. Determinación de la absorción de agua por capilaridad del hormigón endurecido Método Fagerlund. 2008. 5p.

[32] ASTM C 349 - 02. Standard test Method for compressive strength of hydraulic-cement mortars (using portions of prisms broken in flexure). 2002. 3p. ASTM International, United States of America.

[33] ASTM C 305. Standard practice for mechanical mixing of hydraulic cement pastes and mortars of plastic consistency. 1999. 3P. ASTM International, United States of America.

[34] ASTM C109/C109M. Standard test method for compressive strength of hydraulic cement Mortars (using 2-in. or [50-mm] cube specimens). 2002. 6p. ASTM International, United States of America.

[35] ASTM C114-03. Standard test methods for chemical analysis of hydraulic cement. 2003. ASTM International, United States of America. 
[36] Srinivasan, S; Barbhuiya, S. A; Charan, D. \& Pandey, S. P. Characterising cement- superplasticiser interaction using zeta potential measurements. Constr Build Mat 2010; 24: 2517-2521.

[37] Shih, J.; Chang, T. \& Hsiao, T. Effect of nanosilica on characterization of Portland cement composite. Mat Scien Engin A 2006; 424: 266 - 274.

[38] Panesar D.K, Chidiac S.E. Capillary suction model for characterizing salt scaling resistance of concrete containing GGBFS. Cement \& Concrete Composites 2009; 31: 570-576.

[39] Ozyildirim C. and Zegetosky C. Exploratory investigation of nanomaterials to improve strength and permeability of concrete. Transportation Research Record: Journal of Transportation Research Board, No 2142. Nanotechnology in Cement and Concrete. Transportation Research Board of the National Academies, Washington, D.C. 2010; 2: 1-8.

[40] Iqbal K., M. Nanostructure and microstructure of cement concrete incorporating multicementitious composites. Transportation Research Record: Journal of Transportation Research Board, No 2142. Nanotechnology in cement and concrete. Transportation Research Board of the National Academies, Washington, D.C. 2010; 1: 21-27.

[41] Gaitero J.J, Campillo I, Mondal P, and Shah P. Small changes can make a great difference. Transportation Research Record: Journal of Transportation Research Board, No 2142. Nanotechnology in Cement and Concrete. Transportation Research Board of the National Academies, Washington, D. C. 2010; 1: $1-5$.

[42] Pedeferri, P. \& Bertolini, L. La durabilità del calcestruzzo armado, Mc Graw Hill, Milan, 2000.

[43] Mindess, S.; Young, J. and Darwin, D. Concrete, $2^{\text {nd }}$ ed, Pearson Education, New Jersey, USA, 2003. 
[44] Cabeza M, Keddam M, Nóvoa X, Sánchez I \& Takenouti H. Impedance spectroscopy to characterize the pore structure during the hardening process of Portland cement paste, Electrochim Acta 2006; 51: 1831-1841.

[45] Ghafari E, Costa H, Júlio E, Portugal A, Durães L. The effect of nanosilica addition on flowability, strength and transport properties of ultra high performance concrete. Materials and Design 2014; 59: 1-9. 